\title{
Correction to: The consequences of coronavirus outbreak on commodity markets
}

\author{
Himadri Rajput ${ }^{1} \cdot$ Rahil Changotra $^{1} \cdot$ Prachi Rajput $^{2} \cdot$ Sneha Gautam $^{3}$. \\ Anjani R. K. Gollakota ${ }^{4} \cdot$ Amarpreet Singh Arora $^{5}$ (D)
}

Published online: 4 December 2020

(c) Springer Nature B.V. 2020

\section{Correction to: Environment, Development and Sustainability https://doi.org/10.1007/s10668-020-00934-4}

1. Unfortunately, the authors have missed the addition of source of Table 1. We apologize for our mistake.

The source of Table 1 is provided below.

2. There is change in the title of manuscript as it coincides with the title of World Bank report, 2020. We apologize for our mistake

The title has been modified to:

The consequences of Coronavirus outbreak on commodity markets.

The original article can be found online at https://doi.org/10.1007/s10668-020-00934-4.

Sneha Gautam

snehagautam@karunya.edu

Amarpreet Singh Arora

amarpreet.amar007@gmail.com

1 School of Energy and Environment, Thapar Institute of Engineering and Technology, Patiala 147004, India

2 Central Scientific Instruments Organization, Sector 30C, Chandigarh 160030, India

3 Karunya Institute of Technology and Sciences, Coimbatore, Tamil Nadu 641114, India

4 Department of Safety, Health \& Environmental Engineering, National Yunlin University of Science and Technology, Douliou 64002, Yunlin, Taiwan, ROC

5 School of Chemical Engineering, Yeungnam University, Gyeongsan 38541, South Korea 


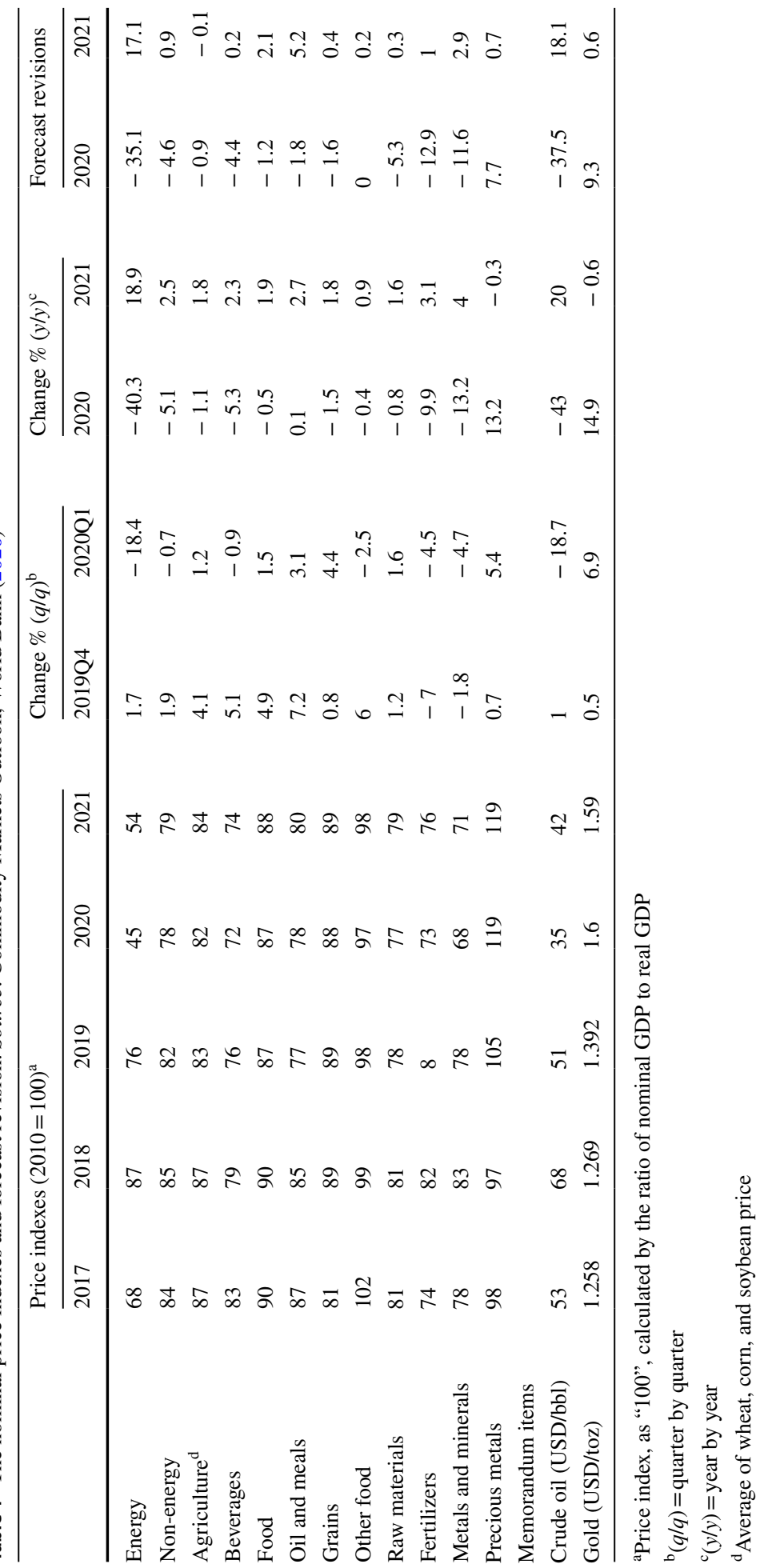




\section{Reference}

Commodity Outlook (2020) A shock like no other: the impact of COVID-19 on commodity markets. Deutsche Bank AG, Frankfurt: Corporate Bank.

Publisher's Note Springer Nature remains neutral with regard to jurisdictional claims in published maps and institutional affiliations. 